\title{
EDREMIT KÖRFEZI'NIN KUZEY SAHIL BÖLGESINDE PEYZAJ PATERNI VE ARAZI ÖRTÜSÜNÜN ZAMANSAL VE MEKÂNSAL DEĞișiMi
}

[*]Şermin Tağıl

Öz:

Arazi kullanımı değişimi, bölgesel, ekonomik ve sosyal gelişsiminde hayati rol oynamaktadir. Bu çallşsmanin amacı, Peyzaj Ekolojisi ilkesine dayalı CBS teknikleri kullanarak Edremit Körfezi'nin kuzey sahil bölgesinde peyzaj paterninin ve arazi örtüsünün zamansal ve mekânsal değişimini nicel olarak ortaya koymak ve açıklamakttr. Bu çalışmada üç farkll Landsat TM ve ETM+ (1987, 2000 ve 2010) uydu görüntüsü kullanulmuştr. Mekânsal desen ve mekânsal heterojenite peyzaj metrikleri hesaplanarak analiz edilmiştir. Hesaplamalar sirasinda hem standart hem de hareketli pencere (moving window) analizleri kullanulmıştr. Peyzaj değişimi ile ilgili olarak, peyzaj yapısından mekânsal dağıllm ve iliş̧kinin yönü tarthşlmışttr. 1987-2010 döneminde, özellikle dağlarda ormanlarda artş ve sahil bölgelerinde yapay alanlarda bir arths fakat zeytinlik ve meyvelerde bir azallş belirlenmiştir. Yoğun ekili tarım alanlarında da belirgin bir azalma tespit edilmişstir. Zeytin ağaçlarını (Olea europaea subsp. europaea) baskn olduğu zeytinlik-meyvelik arazileri inşaa edilmiş arazilere dönüş̧üren kentleşme süreçleri, son yirmi yllda, bölgede peyzaj deseninin zamansal ve mekânsal değissmesine yol açan en önemli etkendir. Sonuçlar peyzaj kompozisyonu ve biçiminin arazi örtüsü değişiminin açıklanmasinda önemli olduğunu ortaya koymuştur. Bölgede artan koruma çabası sadece orman alanlarını korumak için değil geleneksel tarım uygulamaların içeren zeytinliklerin korunmast için de yapılmalıdı.

\section{Anahtar Kelimeler: Arazi örtüsü değişimi, Edremit körfezi, peyzaj ekolojisi, peyzaj paterni, uzaktan algılama.}

\footnotetext{
* Balıkesir Üniversitesi, Fen-Edebiyat Fakültesi, Coğrafya Bölümü, 10100, BALIKESIR email: stagil@balikesir.edu.tr
} 


\title{
Spatiotemporal Change of Land Cover and Landscape Pattern in the North Coastal Region of Edremit Gulf
}

\begin{abstract}
:
Land use change plays vital roles in regional, economic and social development. The objective of this study is to explore and explain quantitatively the spatiotemporal changes of land cover and landscape pattern in the North Coastal Region of the Gulf Edremit, in Egean Sea with GIS Based on the principle of landscape ecology. In this study, three different Landsat TM and ETM+ images (1987, 2000 and 2010) were used. The spatial pattern and spatial heterogeneity are analyzed by employing and computing landscape metric variables. Both standard and moving window analyses were carried out on the datasets. From landscape structure, spatial distribution and relationship aspects discussed about the landscape changes. We measured an increase in forests and especially in mountains, an increase in artificial areas, especially in coastal zones, but a decrease in orchlands in coastal zones during 19872010. Extensively cultivated areas showed a marked decrease. Urbanization processes developed to transfer orchland dominanted with olive trees (Olea europaea subsp. Europaea) into buildup land is the most important force leading to the spatiotemporal change of landscape pattern in the area, in the last two decades. Results indicate that landscape composition and configuration were important in explaining land cover change. We suggest that an increasing conservation effort should be made to protect not only for the forest areas but also the traditional Olive cultuvitation including agricultural practices.
\end{abstract}

Keywords: Landcover change, gulf Edremit, landscape ecology, landscape pattern, remote sensing.

\section{Giriș:}

Günümüzde, arazi kullanımı-arazi örtüsü- (AKAÖ) değişimi sürdürülebilir kalkınmanın temel sorunudur. Hatta peyzaj üzerinde insanın yok edici etkisi olduğu bilinen bir gerçektir (Marsh, 1864). En büyük küresel değişikliğin insanın arazi örtüsü üzerine etkisi olduğunu söylenilebilir (Thomas, 1956). Dolayısı ile günümüz peyzajı doğal süreçler ile insan aktivitelerinin karşılıklı etkileşimin bir sonucu olarak ortaya çıkmış, karmaşık bir sistemdir. 
Akdeniz havzası dünyada yüzlerce yıldır insan baskısı altındadır (Myers vd., 2000). Özellikle Avrupa'nın karakteristik özelliği ovaların kentleşmesi, dağlık alanların tekrar ormanlaştırılması ve kıyı alanlarına yoğun yerleşilmesidir (UNEP 1989). Avrupa peyzajındaki bu dramatik değişikliğe dikkat çekmek için, Doblis Avrupa Çevre Değerlendirmesinde "Peyzajda bir şey yanlış gidiyor" slagonuyla ilk uyarı verilmiştir. Avrupa'da kırsal peyzajın zenginliği ve çeşitliliğinin kıtalar arasında ayırt edici bir özellik olduğu ve bu peyzajların yok olma tehlikesi altında olduğu vurgulanmıştır (Stanners ve Bourdeau, 1995). Tarih boyunca farklı uygarlıklara ev sahipliği eden Türkiye'de de doğal, insan etkisiyle şekillenmemiş, peyzajı bulmak oldukça zordur. Dolayısı ile Türkiye peyzajında da "bir şeylerin yanlış gittiği”" söylenilebilir. İnsan ve doğa arasındaki yakın etkileşimin sonucunda peyzajdaki değişim kaçınılmazdır. Türkiye'de peyzajın üzerinde etkili olan en önemli stres kaynakları: tarımın yoğunlaştırılmasi; tarımsal faaliyetlerin terk edilmesi; kentsel genişleme; altyapı geliştirme (özellikle yollar); turizm-rekreasyon; madencilik ve yaban hayatındaki yaşam (biyolojik zenginlik) kayıplarıdır.

Çoğunlukla insanın etkisi sonucu devamlılık gösteren habitatlarda parçalanma meydana gelmektedir. Bunun sonucu, orijinal habitat özellikleri kaybolmakta ve ünitelerde izolasyon artmaktadır (Primack, 1998). Oysaki peyzaj bütünlüğü ve özellikle koridorları, biyolojik çeşitliliğin korunması ve doğal ekosistemlerin istikrarı bakımından önemlidir (Wiens vd., 1993). Peyzajda parçalılığın artması karşısında türler küçük üniteler arasında hareket etmekte ve zamanla bunların da parçalılığın artışıyla birlikte ortadan kalkması ile türlerin hareketleri de ortadan kalkmaktadır. Bu durum, sadece biyoçeşitlilikte yok oluşa (Hitchings ve Beebee, 1997) değil, sağlıksız kabul edilen kenar habitatlarının ortaya çıkışına da neden olmaktadır (Wilcox ve Murphy, 1985).

İnsan ile peyzaj arasında dikkati çeken ilişsinin bir sonucu olarak 1980'lerin başından beri peyzaj parçalılığındaki değişım, nicel olarak ifade edilmeye çalışılıışır (Jensen, 2000; Bastian, 2001; Coppedge vd., 2001). Birçok çalışmada “Peyzaj Ekolojisi” adıyla ortaya çıkan bu yeni disiplinde zamansal ve alansal heterojenitenin nerede ve ne zaman olduğu farklı peyzaj göstergeleri ile ortaya konulmaya çalışılmıştır (Turner, 1989; McGarigal ve Cushman, 2002; Harper vd., 2005). Tabiî ki Coğrafi Bilgi Sistemleri (CBS) ile Uzaktan Algılama (UA) tekniklerinde ve dolayısıyla dijital veri kaynaklarındaki artış peyzaj ekolojisi çalışmalarında da artışa neden olmuştur (Groom vd., 2006; Dilek ve Uzun, 2007; Newton vd., 2009).

Edremit Körfezi çevresi, özellikle, ikinci konut inşaatı nedeniyle artan nüfusuyla dikkati çeken bir bölgedir. Bu nedenle Edremit Körfezi çevresindeki peyzaj, kentsel genişleme; altyapı geliştirme (özellikle yollar) ve turizm-rekreasyon baskısı altındadır. Dolayısı ile körfez çevresindeki peyzaj, insan baskısı altında şekillenmekte, değişmekte ve kayıplara uğramaktadır. $\mathrm{Bu}$ çalışmada, uydu görüntülerinden yararlanılarak, Edremit Körfezi'nin kuzeyinde bilinen bu insan baskısı altında arazi kullanımı-arazi örtüsü değişiminin ortaya konması; bu değişime bağlı olarak peyzaj paterninde meydana gelen değişimin belirlenmesi; bu değişim sonucunda ortaya 
çıkan habitat parçalılığının ve habitat kalitesinin nicel olarak ortaya konulması amaçlanmıştır. Bu çalışma peyzaj ekolojisi prensiplerinde yapılmıştır.

\section{Materyal ve Metot}

\section{1. Çalışma Alanı}

Çalışma alanı, hızlı kentleşme sürecinde ve aynı zamanda Marmara Bölgesi’nin önemli rekreasyonel arazilerinden olan Edremit Körfezi’nin kuzey sahilini kapsamaktadır (Şekil 1). Yaklaşık olarak Balıkesir'in Edremit ilçesi kuzeyinden Asos-Kadırga kıyılarına kadar uzanmaktadır. Çalışma alanı yaklaşık $721 \mathrm{~km}^{2}$ alan kaplamaktadır. Yaklaşı $1700 \mathrm{~m}$ yükseltiye sahip Kazdağları’nın yamaçları çalışma alanının kuzey sınırını oluşturmaktadır.

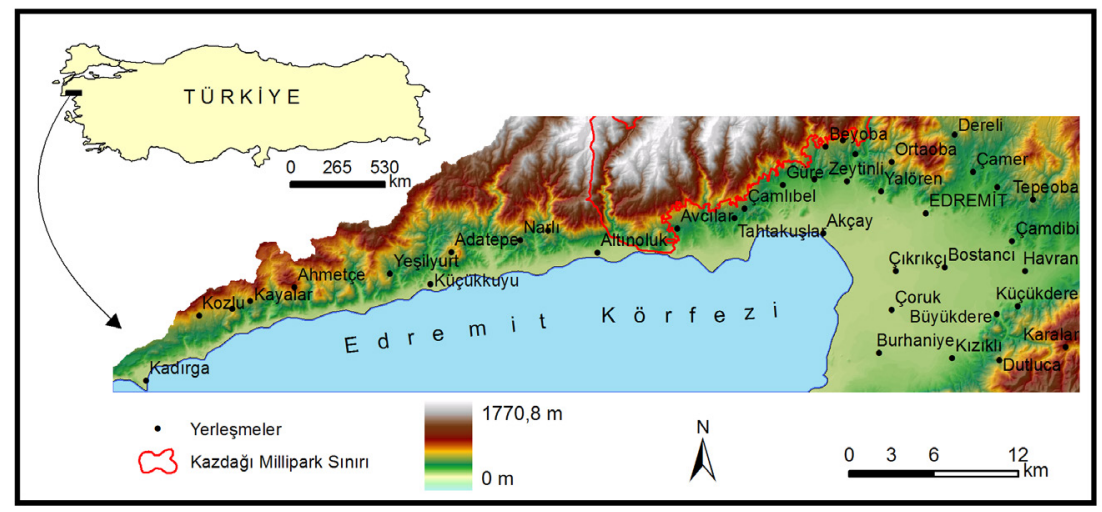

Şekil 1. Çalışma alanının konumu.

Çalışma alanında karakteristik Akdeniz iklime görülmektedir. Bu nedenle de Akdeniz iklimi ve Akdeniz Bölgesinin en karakteristik bitkisi olan zeytinin (Olea europaea subsp. europaea) Türkiye'de yayılış gösterdiği alanlardandır. Thornthwaite iklim sınıflandırmasına göre, Edremit meteoroloji istasyonu verileri dikkate alındığında, çalışma alanı kurak ve az nemli, üçüncü dereceden mezotermal, kış mevsiminde çok kuvvetli su fazlası olan ve denizel şartlara yakın iklim tipine girmektedir $\left(\mathrm{C}_{1}, \mathrm{~B}_{3}, \mathrm{~s}, \mathrm{~b}_{3}{ }_{3}\right)$.

Çalışma alanı içindeki en büyük yerleşme olan Edremit İlçesinin nüfusu TUİK verilerine göre 1927 de 12.000 civarlarındayken, 1990 da 35.000 i aşmış, 2011 genel nüfus sayımına göre ise 125.018 olmuştur. Bu nüfusun 53.826 sı ilçe merkezinde yaşamaktadır. $\mathrm{Bu}$ nüfus artışı ile Edremit belediyesi 1. sınıf belediyeye terfi etmiştir. Yaz dönemiyle birlikte körfez çevresinde nüfus 5-6 kat artmakta saha üzerindeki nüfus baskısı yoğunlaşmaktadır (İrtem vd., 2005). 


\subsection{Malzeme ve Yöntem:}

Bu çalışmada, 30 metre mekânsal çözünürlükteki 16 Haziran 2010 ve 07 Haziran 2000 tarihli Landsat Enhanced Thematic Mapper Plus (ETM+); 11 Mayıs 1987 tarihli Landsat Thematic Mapper (TM) uydu görüntüleri kullanılmıştır. Uydu görüntülerinin sınıflandırılması "Hybrid supervised-unsupervised classification" yöntemi ile yapılmıştır (Messina vd., 2000; Crews-Meyer, 2001). Sınıfların değerlendirilmesi, tayf özellikleri, mevcut GPS verileri, arazi gözlemleri ve hâlihazır arazi kullanımı haritaları yardımıyla yapılmış; 6 farklı arazi kullanımı-arazi örtüsü sınıfı oluşturulmuştur (Şekil 2). Sınıfların genel doğruluğu (overall accuracy) \% 80 nin üzerinde; kappa katsayıları ise 0.75 in üzerindedir. Çalışmada temel alınan sınıflar; Su Yüzeyleri (kanallar, akarsular, tarım amaçlı su rezervleri), Orman ve Çalılık Arazi (doğal ağaçlıklar), Zeytinlik-Meyvelik Arazi, Ekili Tarım Arazileri, İnşa Edilmiş Arazi (yapay yüzeyler, yerleşme, yol, otel, havaalanı gb.) ve Çıplak Toprak ile Taş Yüzeyleridir (Şekil 2). Bu sınıflardan zeytinlik ve meyveliklerde, Edremit Ovasında narenciye; yamaçlarda ise Olea europaea subsp. europaea baskındır. Çıplak taş ve toprak yüzeyleri, otlak ve mera arazisi ile karışmış durumdadır. Görüntünün alındığı dönem ilkbahar sonu ve yaz başı olduğu için otlakların çıplak yüzeylerle benzer yansımayı verdiği için ayrımı yapılamamıştır. Sınıflandırmadan sonra değişimin yönü belirlemede en uygun yöntemlerden biri olan "post-classification change-detection method" (Wickware ve Howarth, 1981) kullanılarak arazi kullanımı- arazi örtüsünde 1987-2000, 2000-2010 ve 19872010 dönemlerine ait değişimin yönü ortaya konulmuştur.

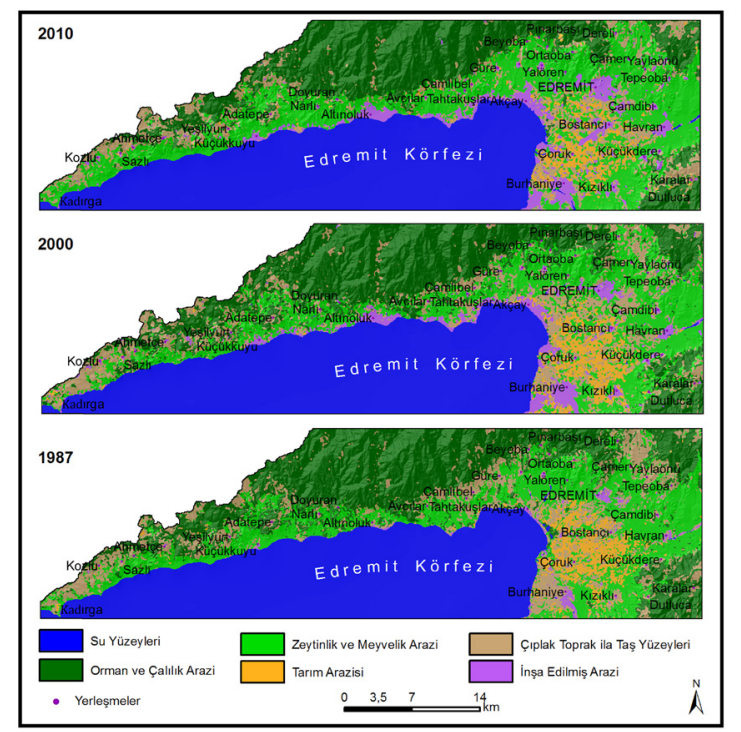

Şekil 2. 1987, 2000 ve 2010 yıllarında arazi kullanımı ve arazi örtüsü. 
Edremit Körfezi kuzeyinde arazi kullanımında meydana gelen değişimin şiddeti peyzaj patern metrikleri ile ortaya konmuştur (McGarigal ve Marks, 1995; Turner vd., 2001). İnsan-çevre etkileşimini göstermesi bakımından önemli olan, diğer bir deyişle parçalılığı ifade eden, sınıf ve peyzaj düzeyinde farklı patern göstergeleri, peyzajın alan, kenar, şekil ve dağılım özelliklerini gösterebilmek amacıyla analiz edilmiştir. Hesaplanan metrikler Çizelge 1 de gösterilmiştir. Metriklerle ilgili ayrıntılı bilgi McGarigal ve Marks (1995) dan elde edilebilir.

Peyzaj düzeyinde yapılan metrik hesaplamaları ile incelenen dönem içinde genel peyzaj düzeyindeki değişiklik Çizelge olarak ortaya konmuştur. Ancak, tek sonuç halinde verilen standart metrikler ile mekândaki yatay değişimin anlaşılması oldukça zordur. Okuyucuya kolaylık getirmesi amacıyla, peyzajda mekânsal heterojeniteyi ve değişikliği gösterebilmek amacıyla ise hareketli pencere (moving window) analizi yapılmış; standart peyzaj metrik sonuçlarından CONTAG görselleştirilmiştir (Milne, 1988; McGarigal ve Marks, 1995). Hareketli pencere analizi ekolojide fraktal peyzajların analizinde tercih edilen bir yöntemdir (Turner ve Ruscher, 1988; Milne, 1991; McGarigal vd., 2002). Analizde 30 m çözünürlükte grid görüntüler, $450 \times 450 \mathrm{~m}$ çap ve 8 piksel komşuluk ilişkisi kullanılmıştır.

Çizelge 1. Seçilmiş bazı metrikler ve bu metriklerle ilgili genel açıklama.

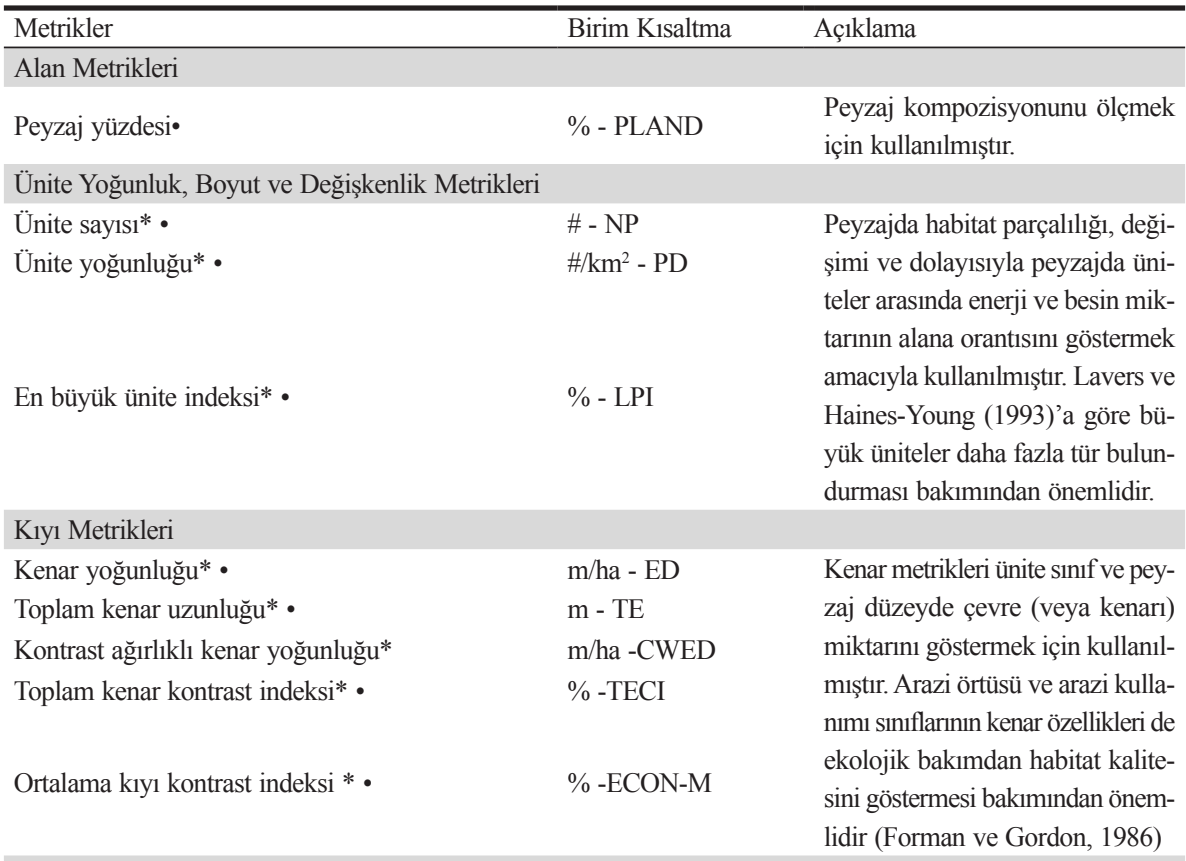

Şekil Metrikleri 


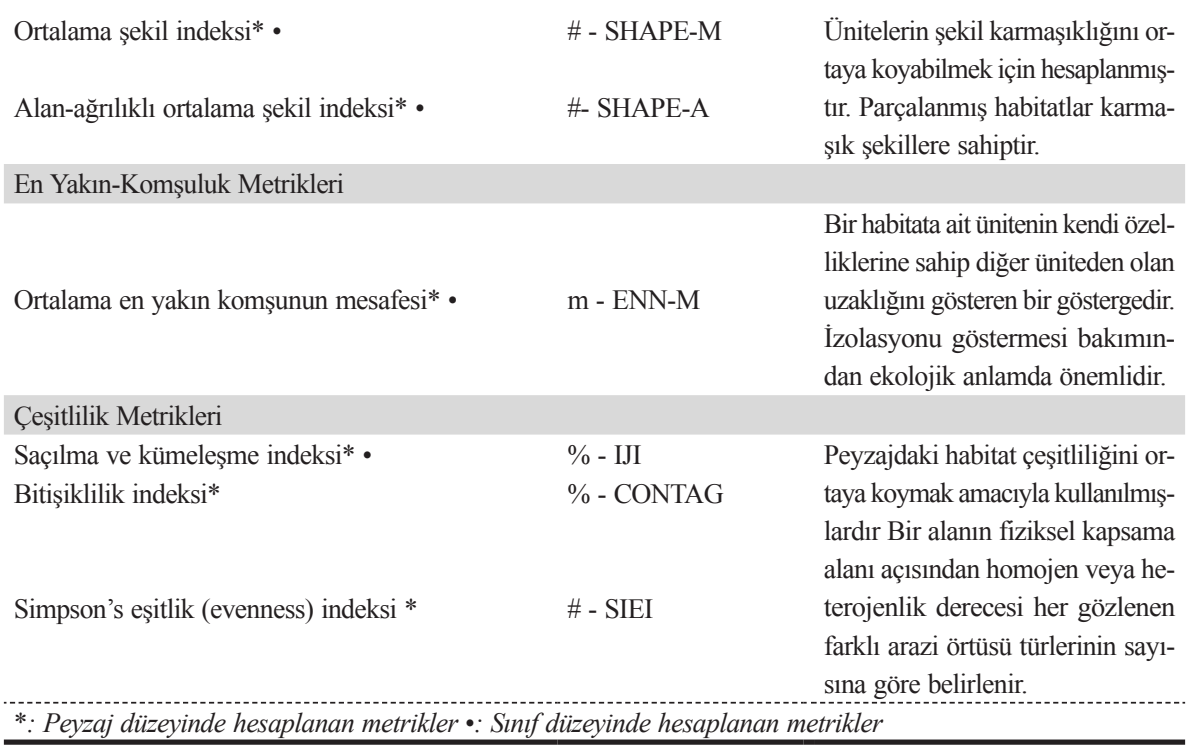

\section{Bulgular}

\subsection{Arazi Kullanımı ve Arazi Örtüsü Değişimin Yönü}

Arazi kullanımı-arazi örtüsünde 1987-2000, 2000-2010 ve 1987-2010 dönemlerinde gerçekleşen değişim Çizelge 2 ve Şekil 3 te gösterilmiştir. Bu çizelgeden elde edilen sonuçlar şunlardır:

1987-2000 döneminde orman ve çalılık arazinin \%6.7 si, 2000-2010 döneminde ise \%7.7 si zeytinlik-meyveliklere dönüşmüştür. Bu dönüşüm genellikle zeytinlikler içinde parça parça daha önceki dönemlerden kalan orman alanlarında gerçekleşmiştir. İncelenen dönem içinde, orman ve çalılık yüzeylerden çılak taş ile toprak yüzeylere olan dönüşüm de artmıştır. Ormanlık ve çalılık araziden özellikle zeytinlik-meyvelik arazilere olan bu dönüşüm karşısında, zeytinlik-meyvelik araziden ise inşa edilmiş yüzeylere doğru bir değişim söz konusudur. Bu arazi dönüşümünde özellikle deniz kenarındaki zeytinlik araziler ikincil konut alanlarına dönüştürülürken; zeytinliklerin içindeki ve üst kuşağındaki ormanlıkçalılık arazinin ise zeytinliklere dönüştürülmesi şeklinde olmuştur. Yapılan analizler zeytinlik kuşağının üzerinde ortalama 350-700 metreler arasında, kızılçam (Pinus brutia Ten.) ların baskın olduğu orman kuşağıyla olan dokunağın 1987-2000 döneminde arttığını göstermektedir. Edremit Körfezi çevresinde tarım arazilerinde ise daha çok zeytinlik ve meyvelik araziye dönüşüm söz konusudur. Tarım arazilerinden olan bu dönüşümde özellikle narenciye dikimleri etkili olmuştur. Yine tarım arazilerinden 2010 yılında da devam eden 
inşa faaliyetlerinin olduğu görülmektedir. Bu dönüşüm, 2000-2010 döneminde 1987-2000 döneminden fazla olmuştur. Diğer yandan görüntü incelemeleri, Edremit Ovasında 1987 yıllarında genellikle tarımsal faaliyetlerin yapıldığı, fakat 2010 yılında ova tabanları üzerinde zeytinlik-meyveliklerin oluşturulduğu tespit edilmiştir.

Çizelge 2. 1987-2000, 2000-2010 ve 1987-2010 dönemlerinde arazi kullanımı ve arazi örtüsünde değişimin yönü (\%).

\begin{tabular}{|c|c|c|c|}
\hline Değişimin yönü & $1987-2000$ & $2000-2010$ & $1987-2010$ \\
\hline Hep Orman ve Fundalık Arazi & 84,6 & 82,8 & 77,4 \\
\hline Orman-Çalılık Arazi İken Zeytinlik ve Meyvelik Arazi Olan & 6,7 & 7,7 & 9,5 \\
\hline Orman-Çalılık Arazi İken Çıplak Toprak ilâ Taş Yüzeyi Olan & 8,0 & 9,0 & 11,9 \\
\hline Orman-Çalılık Arazi İken İnşa Edilmiş Arazi Olan & 0,6 & 0,4 & 1,1 \\
\hline Hep Zeytinlik ve Meyvelik Arazi & 83,4 & 94,3 & 88,0 \\
\hline Zeytinlik ve Meyvelik Arazi İken İnşa Edilmiş Arazi Olan & 16,6 & 5,7 & 12,0 \\
\hline Hep Tarım Arazisi & 76,3 & 54,9 & 56,9 \\
\hline Tarm Arazisi iken Zeytinlik ve Meyvelik Olan & 19,8 & 33,3 & 33,2 \\
\hline Tarım Arazisi iken İnșa Edilmiş Arazi Olan & 3,9 & 11,8 & 9,9 \\
\hline Hep Çıplak Toprak Yüzeyi & 62,1 & 55,4 & 48,1 \\
\hline Çıplak Toprak ilâ Taş Yüzeyi iken Zeytinlik ve Meyvelik Olan & 24,8 & 37,7 & 36,7 \\
\hline Çıplak Toprak ilâ Taş Yüzeyi iken İnşa Edilmiş Arazi Olan & 13,0 & 6,8 & 15,1 \\
\hline
\end{tabular}

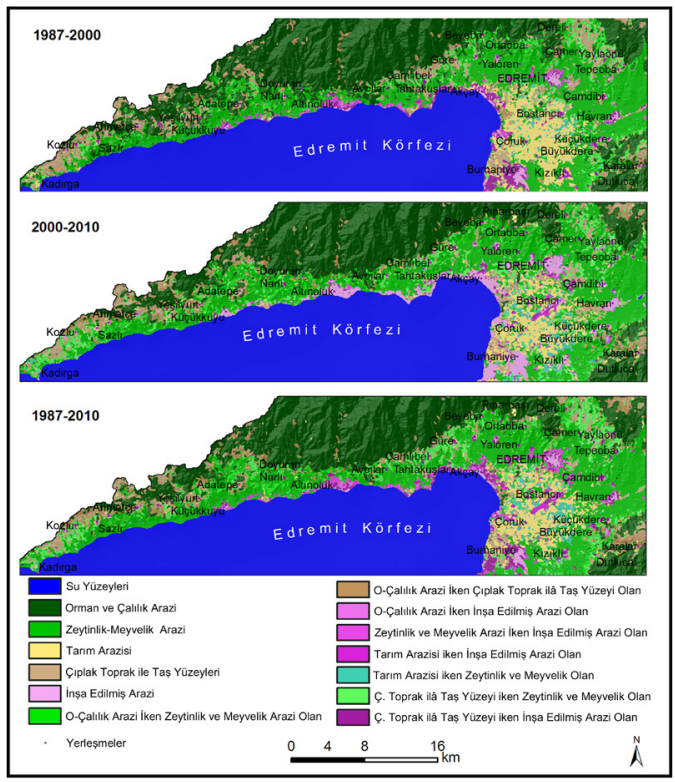

Şekil 3. 1987-2000, 2000-2010 ve 1987-2010 dönemlerindeki değişim yönü. 


\subsection{Peyzaj Paterni:}

1987, 2000 ve 2010 yıllarına ait farklı paten göstergeleri hesaplanarak habitat özellikleri ve değişimleri ile ilgili bilgi elde edilmeye çalışılmıştır. Analiz sonuçları Çizelge 3 ve 4 te gösterilmiştir.

Buna göre çalışma alanındaki PLAND değerlendirildiğinde, bütün yıllarda orman-çalılık arazinin oranının yüksek olduğu görülmektedir (Çizelge 3). Baskın sınıf olmakla birlikte bu sınıfin genel peyzaj içindeki oranı zaman içinde azalma göstermiştir. Peyzaj genelinde PLAND daki en belirgin artış ise inşa edilmiş yüzeylerde gözlenmiştir.

Çizelge 3. 1987, 2000 ve 2010 yıllarına ait sınıf düzeyinde patern göstergeleri. 1: Orman ve Çalılık Arazi, 2: Zeytinlik ve Meyvelik, 3: Tarım Arazisi, 4: Çıplak Taş ve Toprak Yüzeyi, 5: İnşa Edilmiş Arazi

\begin{tabular}{|c|c|c|c|c|c|c|c|c|c|c|c|c|}
\hline \multirow{3}{*}{ AKAÖ } & \multicolumn{12}{|c|}{ SINIF METRIKLERİ } \\
\hline & \multirow{2}{*}{$\begin{array}{l}\text { PLAND } \\
(\%)\end{array}$} & \multirow{2}{*}{$\begin{array}{l}\text { NP } \\
\text { (\#) } \\
\end{array}$} & \multirow{2}{*}{$\begin{array}{l}\text { PD } \\
\text { (\#/100ha) }\end{array}$} & \multirow{2}{*}{$\begin{array}{l}\text { LPI } \\
(\%) \\
\end{array}$} & \multirow{2}{*}{$\begin{array}{l}\text { ED } \\
(\mathrm{m} / \mathrm{ha})\end{array}$} & \multirow{2}{*}{$\begin{array}{l}\text { TE } \\
\text { (m) }\end{array}$} & \multicolumn{4}{|c|}{ SHAPE_MSHAPE_AENN_M TECI } & \multicolumn{2}{|c|}{ ECON_M IJI } \\
\hline & & & & & & & (\#) & $(\#)$ & $(\mathrm{m})$ & $(\%)$ & $(\%)$ & $(\%)$ \\
\hline & & & & & & & \multicolumn{6}{|c|}{1987 Yili } \\
\hline 1 & 42,34 & 768 & 0,57 & 14,68 & 10,98 & 1479930 & 1,29 & 7,64 & 195,73 & 72,67 & 66,91 & 57,29 \\
\hline 2 & 31,1 & 1057 & 0,78 & 9,39 & 15,33 & 2066790 & 1,29 & 13,58 & 137,74 & 72,07 & 73,52 & 75,95 \\
\hline 3 & 5,26 & 457 & 0,34 & 1,43 & 4,45 & 600570 & 1,24 & 6,96 & 276,74 & 65,34 & 65,93 & 68,39 \\
\hline 4 & 20,06 & 1548 & 1,15 & 0,88 & 17,01 & 2293680 & 1,34 & 4,23 & 155,89 & 94,51 & 95,5 & 82,38 \\
\hline \multirow[t]{2}{*}{5} & 1,24 & 259 & 0,19 & 0,13 & 1,42 & 191190 & 1,23 & 2,3 & 389,26 & 58,15 & 60,9 & 54,19 \\
\hline & & & & & & & \multicolumn{6}{|c|}{2000 Y 11} \\
\hline 1 & 39,71 & 481 & 0,36 & 16,07 & 8,44 & 1138470 & 1,27 & 7,99 & 272,28 & 71,23 & 69,14 & 61,07 \\
\hline 2 & 29,76 & 660 & 0,49 & 6,9 & 13,91 & 1875990 & 1,35 & 9,47 & 207,75 & 76,78 & 71,61 & 81,19 \\
\hline 3 & 5,09 & 346 & 0,26 & 1,45 & 3,92 & 527910 & 1,28 & 6,34 & 359,65 & 72,33 & 72,32 & 80,36 \\
\hline 4 & 19,65 & 1136 & 0,84 & 0,93 & 14,92 & 2011140 & 1,35 & 3,3 & 201,36 & 93,46 & 93,33 & 84,47 \\
\hline \multirow[t]{2}{*}{5} & 5,8 & 308 & 0,23 & 0,47 & 3,21 & 432150 & 1,29 & 2,37 & 415,44 & 70,37 & 74,84 & 87,35 \\
\hline & & & & & & & \multicolumn{6}{|c|}{2010 Yilı } \\
\hline 1 & 34,68 & 287 & 0,21 & 14,67 & 5,56 & 749610 & 1,27 & 6,13 & 308,02 & 73,45 & 71,11 & 64,62 \\
\hline 2 & 37,44 & 458 & 0,34 & 12,7 & 12,04 & 1622580 & 1,29 & 13,05 & 210,83 & 78,71 & 75,3 & 85,02 \\
\hline 3 & 4,17 & 447 & 0,33 & 0,6 & 3,93 & 529590 & 1,25 & 3,36 & 374,91 & 68,49 & 67 & 78,64 \\
\hline 4 & 16,45 & 1071 & 0,79 & 0,44 & 13,16 & 1773660 & 1,36 & 2,82 & 202,28 & 91,62 & 90,97 & 87,11 \\
\hline 5 & 7,26 & 361 & 0,27 & 0,52 & 3,81 & 513180 & 1,26 & 2,61 & 343,15 & 71,48 & 76,96 & 77,34 \\
\hline
\end{tabular}

Çizelge 4. 1987, 2000 ve 2010 yılları peyzaj düzeyinde patern göstergeleri.

\begin{tabular}{lllllllllllllllll}
\hline \multicolumn{1}{c}{ PEYZAJ İNDEKSLERI } & & & & & & & & & & & \\
Yillar & NP & PD & LPI & TE & ED & CWED & TECI & ECONM & SHAPEM & SHAFEA & ENN_M & CONTAG & IJ & SIEI \\
& & & & & & & & & & & & & & & & \\
1987 & 4089,00 & 3,03 & 14,68 & 3316080 & 24,60 & 20,15 & 72,45 & 78,96 & 1,30 & 8,70 & 186,97 & 51,19 & 73,81 & 0,85 \\
2000 & 2931,00 & 2,17 & 16,07 & 2992830 & 22,20 & 18,59 & 73,14 & 80,05 & 1,32 & 7,10 & 255,62 & 48,50 & 80,32 & 0,89 \\
2010 & 2624,00 & 1,95 & 14,67 & 2594310 & 19,24 & 16,27 & 72,26 & 80,05 & 1,30 & 7,81 & 264,13 & 49,79 & 82,81 & 0,88 \\
\hline
\end{tabular}

Peyzajda parçalılığı ve değişimi göstermek amacıyla ünite yoğunluğu, büyüklüğü ve değişkenliği metrikleri, kullanılmıştır. Bu metriklerden NP ve PD incelediğinde dönemsel 
farklılıkların olduğu görülmektedir (Çizelge 3). Genellikle inşa edilmiş araziler hariç diğerlerinde NP azalma eğilimi görülmektedir. Ekili tarım alanlarındaki NP da 1987-2000 döneminde düşme; daha sonra ise artış tespit edilmiştir. Genel peyzaj düzeyinde çalışma alanı incelendiğinde de NP azalmıştır (Çizelge 4). Ancak burada önemli olan bir diğer unsur ise en büyük habitatın özelliğidir. Bu kapsamda LPI peyzaj parçalılığını gösteren en etkili metriklerden biridir. Lavers ve Haines-Young (1993)'a göre büyük üniteler daha fazla tür bulundurmaktadır. Peyzajın \%14-16 sı tek bir üniteyle kaplıdır (Çizelge 4). Bu ünite incelenen bütün dönemlerde orman- çalılık yüzeyine aittir. Zeytinlik- meyvelik arazide en büyük ünitenin peyzaj içindeki oranı 1987-2000 döneminde düşerken; 2000 döneminde artma göstermiştir.

Peyzaj parçalılı̆̆ının bir diğer göstergesi olan kenar metriklerinden ED ve TE hesaplanmıştır. Sonuçlar göstermektedir ki inşa edilmiş araziler dışındaki sınıflarda kenar yoğunluğu azalmıştır. Üniteler ve komşuları arasındaki kontrast da ekolojik açıdan önemli bir diğer metriktir (Forman ve Godron, 1986). Çünkü peyzajdaki izolasyon bir ekolojik bölge ile diğeri ile bağlarının azaldığını göstermektedir. Arazi kullanımı sınıflarından ormanlık- çalılık alanlar ve zeytinlik-meyvelik alanlarda kıyı kontrat indeksleri zaman içerisinde çok büyük artış göstermemekle birlikte \%2-3 artış göstermiştir. Oysaki ED ve TE söz konusu dönem içinde azalmıştır. Bu azalmaya rağmen kenar kontrası artmıştır. En büyük kontrast artışı ise inşa edilmiş arazilerde olmuştur (ECON-M ve TECI). Ancak bu arazi kullanımı sınıfında TE ve ED artış eğilimdedir. Bu da inşa edilmiş arazilerde kontrast artışının normal kabul edilebileceğini göstermektedir. Genel peyzaj düzeyinde ise TE ve ED düşüş göstermiştir (Çizelge 4). Bu sonucu CWED, TECI ve ECON_M da desteklemektedir. Bu göstergelerde yaklaşık olarak \% 2 lik bir değişiklik vardır. Ancak üç dönemde de peyzaj içindeki kıyı kontrastı $\% 70$ in üzerinde olması oldukça yüksek kontrastın olduğunu göstermektedir.

Peyzaj düzenini ortaya koyabilmek amacıyla şekil metrikleri hesaplanmıştır (Milne, 1988). SHAPE_M ve SHAPE_A metriklerinin 1'den büyük olması, şekilsel olarak ünitelerin düzenli yuvarlak ya da kare şekle sahip olmadığını göstermektedir. Diğer yandan alan ağırlıklı şekil indeksinin ortalama şekil indekslerinden büyük olduğu tespit edilmiştir. $\mathrm{Bu}$ en büyük ünitenin diğerlerinden daha düzensiz şekle sahip olduğunu ve parçalılığının fazla olduğunu göstermesi bakımından önemlidir. Genel peyzaj düzeyinde ise şekil metriklerinde çok belirgin bir değişikliğin olmadığı tespit edilmiştir (Çizelge 4).

ENN_M, bir ünitenin kendi özelliklerine sahip diğer üniteden olan uzakl1ğını (izolasyonu) gösteren bir göstergedir. Özellikle bitki ve hayvan yaşamı aç1sından önemli olan ve çalışma alanında insan etkileşiminden en çok etkilenen AKAÖ sınıfları olan orman-çalılık, zeytinlik -meyvelik ve tarım arazilerinde en 
yakın komşunun ortalama mesafesi artış eğilimindedir. IJI ve SIEI indekslerin sonuçları bütün sınıfların genel peyzaja saçıldığını göstermiştir (>70). CONTAG in 1987 de, 2010 yılına göre daha yüksek olması peyzajda artan düzensizlikler olduğunu göstermektedir (Çizelge 4, Şekil 4).

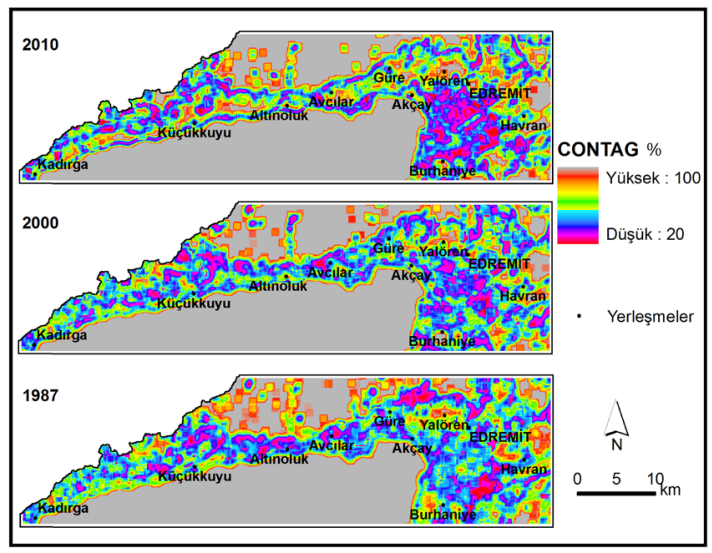

Şekil 4. 1987, 2000 ve 2010 da peyzaj genelindeki CONTAG haritası

Şekil 4 incelendiğinde CONTAG değerinin peyzaj genelinde $\% 0$ ile $\% 100$ arasında değiştiği görülmektedir. \%100 olduğu yerler sadece bir üniteden oluşan peyzajı; yüksek değer aldığı yerler birkaç büyük bitişik üniteden olan peyzaj1; düşük değer aldığı yerler birçok küçük üniteden oluşan peyzaj1, \%0 olduğu yerler ise peyzajdaki bütün ünitelerin farklı olduğu peyzajı göstermektedir (O’Neil vd., 1988). CONTAG doğal olarak bir tek s1nıftan oluşan ve bu sınıfin yeknesak olduğu deniz ve Kazdağları'nın yüksek kısımlarında \%100 dür. CONTAG Küçükkkuyu-Akçay arasındaki yamaçlarda, Edremit Ovası ve Havran-Burhaniye arasında düşük değer almıştır.

\section{Tartışma ve Sonuç}

Edremit Körfez’i kuzeyinde peyzaj değişimi ile parçalılığını nicel olarak göstermek amacıyla uydu görüntüleri ve farklı peyzaj patern göstergelerinden yararlanılmıştır. Çalışma alanında uzaktan algılama ve peyzaj ekolojisi teknikleri, peyzaj paternindeki ekolojik süreçleri anlamada önemli sonuçlar vermiştir. Bu kapsamda peyzaj patern metrikleri, sınıf ve peyzaj düzeyinde test edilmiştir.

Hızlı gelişen turizm ve buna bağlı olarak inşa alanlarının genişlemesi iki yönlü kaynak tahribatına neden olmuş; bir yandan Edremit ovasındaki ekili ve yamaçlardaki dikili tarım arazileri etkilemiş, diğer yandan ise kırsal nüfusun gelir arayışına bağlı olarak yeni zeytinlik alanların oluşturulması nedeniyle yükseklerdeki ormanlık araziyi etkilemiş̧ir. 
Sadece yükseklerde ki orman arazisi değil Edremit Ovasındaki tarım alanları da zeytinliklere dönüştürülmeye başlanmıştır. Bu nedenle zeytinlik ve meyveliklerin peyzaj içindeki oranı 1987-2000 döneminde düşerken, 2010 dönemine tekrar artmıştır. Benzer sonuç Kocadağlı (2009) ile İrtem ve Karaman (2004) tarafindan da tespit dilmiştir. Kentsel gelişimin hem tarım alanları hem de orman alanlarında meydana gelmesi ciddi bir kaynak tahribatının göstergesi olarak değerlendirilmektedir (Alphan, 2006). Ancak bu genişlemeye rağmen zeytinliklerin süründürülebilir kullanıldığı söylenilemez. Çünkü bölgede zeytinlikler hala zeytinlik içi çeşitliliğin azalması, marjinal zeytin yetiştirilen toprakların terk edilmesi, kentleşme, eski bahçe alanlarının farklı amaçlarla kullanımı da dahil olmak üzere birçok faktör tarafından tehdit edilmektedir. Bu stres kaynakları Migliorini (2011) nın da belirttiği gibi zeytinliklerin korunması ve sürdürülebilir kullanımı açısından önemlidir.

Baskın arazi örtüsü sınıfı ormanlık arazi olmakla birlikte genel peyzaj içindeki oranı zaman içinde bu iki yönlü tahribin bir sonucu olarak azalmıştır. Bu azalışta özellikle zeytinliklerin arasında yer alan orman ünitelerinin zaman içinde yok edilmesin etkisi büyüktür (Foto 1). Nitekim Foto 1 de görüldüğü gibi hala tek tek Pinus brutia Ten. ormanlarına ait ağaçlar zeytinliklerin içinde varlıklarını korumuştur. Bu kalıt ağaçlar orman habitatındaki kayıplara kanıt olmaları bakımından ekolojik öneme sahiptirler. Diğer taraftan en büyük üniteyi de oluşturan Kazdağları'ndaki orman arazisindeki koruma faaliyetleri de ünite sayısının düşmesine neden olmuştur. Nitekim Kazdağları Milli Parkı'nın büyük kısmı çalışma alanı içinde kalmaktadır (Tağıl, 2006). İşte bu değişim ormanlık-çalılık arazilerde parçalılığı azaltmıştır. Ormanlık alanlardaki bu değişime karşın hızlı kentleşme ve parça parça yapılan ikincil konutların bir sonucu olarak inşa edilmiş arazilerde ünite sayısı ve yoğunluğu artmıştır (Foto 2). Zeytinlik-meyveliklere ait ünitelerin sayılarının arazi genelinde azalması ise peyzaj içindeki oranı dikkate alındığında parçalanmanın etkisiyle ünite kayıplarının meydana gediğinin bir diğer kanıtıdır. Zeytinliklere ait ünitelerdeki azalış fragmantasyonun azalması şeklinde yorumlanmamalıdır. Ekili tarım alanlarındaki ünite sayısının 1987-2000 döneminde düşmesindeyse 1987'se ovada kötü drenaj şartları nedeniyle parçalı olarak yapılan tarımsal faaliyetlerin ortaya çıkardığı ünitelerin, drenaj şartlarının iyileştirilmesiyle, birleşmesi etkilidir. Ancak daha sonraki dönemde tekrar artmış olmasında ise Edremit ovası dışındaki alanlarda yeni tarım alanlarının elde edilmesinin etkili olduğu hipotez edilmektedir.

Özellikle odunsu türlerin hâkim olduğu arazilerde parçalılığın artması ve hatta ünite kayıplarının meydana gelmesi, başta kuşlar olmak üzere birçok vahşi yaşam türleri için tehlike oluşturmaktadır (Johnson ve Schwartz, 1993). Gerçekleşen ünite kayıpları izolasyonu artırmakta bu da, iki alan arasındaki vahşi yaşamdaki hareketliliği de azaltmaktadır. Fahrig (1997) e göre geriye kalan habitatlarda parçalılıktan ziyada kayıplar ya da değişiklikler, 
türlerin yok olması üzerinde baskın etkiye sahiptir. Çalışma alanında da mevcut fauna türlerinde kayıplar yaşanmış olabilir. Bu konuyla ilgili yapılmış çalışma bulunmamaktadır.

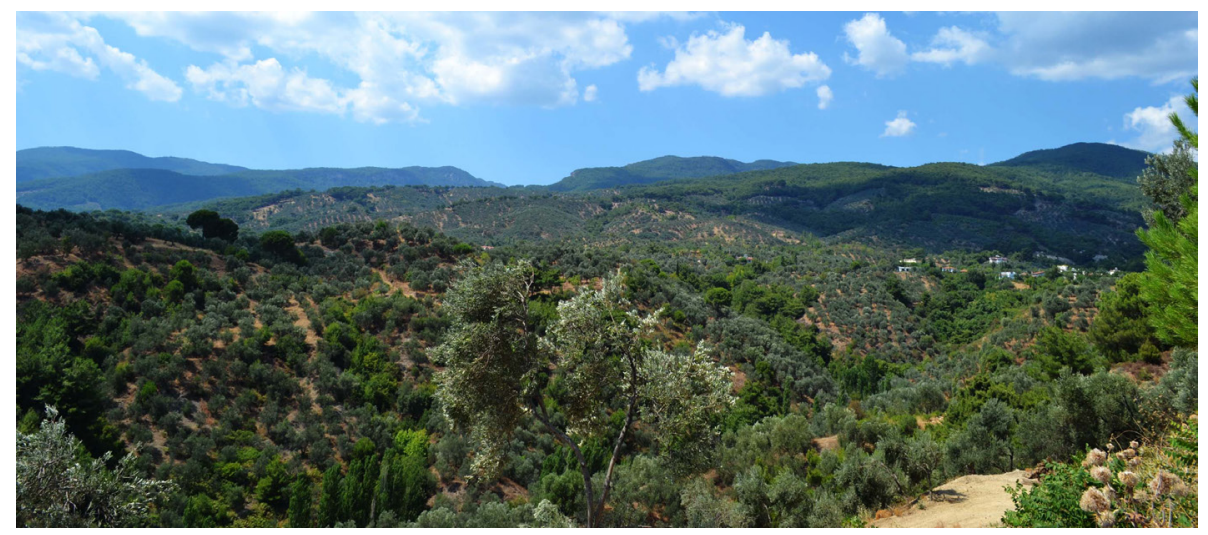

Foto 1. Zeytinli yakınlarında zeytinlikler ve kızılçam (Pinus brutia Ten.) ağaçları

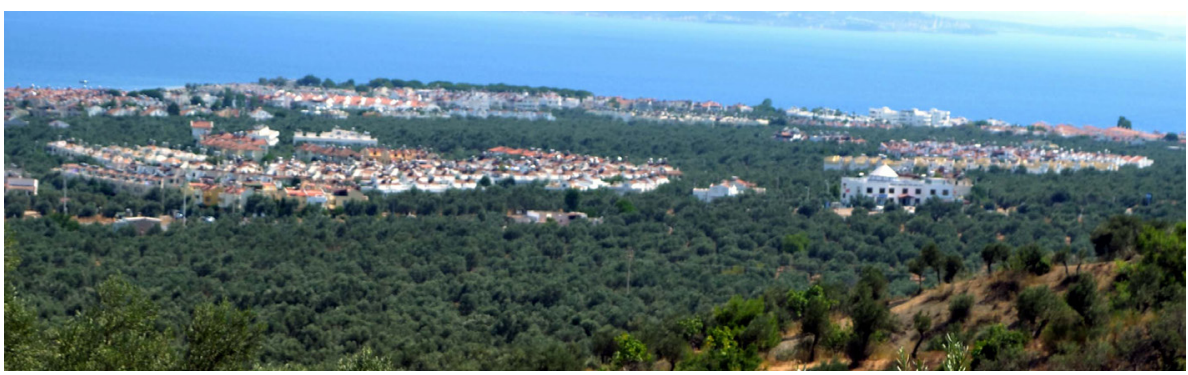

Foto 2. Küçükkuyu Çevresinde Zeytinliklerdeki parçalanmadan görüntü

Peyzaj genelinde en büyük ünitenin oranının düşük olması; dolayısı ile peyzajı homojen yapacak kadar büyük olmaması ve kıyı yoğunluğu ile kıyı uzunluğu düşerken kontrastın artması çalışma alanının homojen olmadığını ve heterojen yapısının arttığını göstermektedir. En büyük ünitenin peyzaj içindeki oranının belirgin bir değişiklik gözlenmemesine rağmen, kıyı yoğunluğu ve uzunluğunun azalması bölgede hılı bir değişimin olduğunu ve bu değişimin sonucunda bazı ünitelerin ortadan kalktığını göstermektedir. Kıyı yoğunluğu türlerin merkeziyetçilik özelliği üzerinde etkilidir; bazı türler kenarda bazı türler ise merkezde yaşamlarını sürdürmektedir (McGarigal ve Marks, 1995). Bu kapsamda çalışma alanındaki canlı türlerinin daha çok kenar habitatları sevenler olduğu söylenilebilir. Çalışma alanında zaten küçük alanlardan oluşan habitatlarda kenar yoğunluğunun azalması, kenar yaşam koşullarına uyum sağlamış türlerin de yok oluşuna neden olabileceği hipotezini ortaya koymaktadır. Çalışma alanında habitat parçalanması peyzaj genelinde şekilsel düzensizliğe de neden olmuştur. Hatta bu insan etkileşimiyle Edremit Körfezi’nin 
kuzeyinde bitki ve hayvan yaşamı açısından önemli olan büyük habitatın habitat kalitesinin bozduğunu ortaya koymaktadır (McGarigal ve Marks, 1995).

Birçok küçük habitattan oluşan alanlar genelde körfezin kuzeyinde Kazdağları'nın alçak yamaçları ve Edremit Ovasıdır (CONTAG $\approx 0$, Şekil 5). Zaman içinde sadece insanın etkisiyle parçalanmanın yoğunlaştığı bölgeler değişmiştir. Şöyle ki, 1987 yılında Küçükkkuyu-Akçay arasındaki tüm yamaçlarda ve Havran-Burhaniye arası parçalanmanın ve dolayısıyla peyzaj değişiminin yüksek olduğu bölgedir. Bu dönem tahribin geniş alanlı olması ile dikkati çekmektedir. 2000 y1lında ise Edremit Ovasında ve Kazdağları yamaçlarının yüksek kesimlerinde insanın peyzaj üzerine baskısı artmıştır. Nitekim bu dönem ovanın yoğun şekilde tarıma açıldığı dönemdir. 2010 a gelindiğinde ise Edremit Ovasında insanın peyzaj üzerin baskısının hala devam ettiği görülmektedir. Bu dönemde körfezin kuzeyinde iki kuşak dikkati çekmektedir. Bunun biri deniz kıyıları ki ikincil konutlar nedeniyle yapılanmanın yüksek olduğu kesim. Bir diğeri ise zeytinliklerin üst kuşağı yani orman sınırıdır. Bu kesimde ise yeni zeytinliklerin oluşturulması söz konusudur ve tahrip yükssektir. Şekil 5 da gözlenen bu iki kuşak çalışma alanında insan baskısı altında olan iki $s l-$ cak noktadır (Hot points) ve arazi planlayıcıları tarafindan dikkate alınmalıdır.

Kısaca yapılan peyzaj patern metrikleri, arazi kullanımı-arazi örtüsü bakımından Edremit Körfez’i kuzeyinde heterojen peyzaj mozaiğinin varlığını; hatta bitki örtüsüne bağlı habitatlarda kayıplarının yaşandığını; aynı özellikteki habitatların arasındaki komşuluk ilişkisinin azaldığını göstermiştir. Edremit Körfezi kuzeyinde artan parçalanma ve izolasyon nedeniyle bazı türlerin yaşam ortamlarının tehlike altına girdiği ve habitat kalitesinin azaldığı şeklinde hipotez edilebilir. Sonuçlar, çalışma alanının, son yıllarda dikkati çeken nüfus ve arazi örtüsü arasındaki karmaşı ilişkinin yaşandığı küresel problemin bir parçası olduğunu göstermektedir (Riebsame vd., 1994). Bölgede insanların bitki örtüsü üzerine etkisi, Akdeniz ülkelerinde de benzer sonuçları ortaya koymuştur (Naveh ve Dan 1973, Tzanopoulos vd., 2005). Zeytinlik alanlardaki dönüşümün aynısı Edremit Körfezinin karşısındaki Levos (Midilli) adasında da gözlenmektedir. Lesvos adasında da turizm aktivitelerinin artması Olea europaea subsp. Europaea dikili arazilerde kayıplara neden olmuştur (Loumou vd., 2000). Hurley ve Arı (2011) anketlerle yapmış oldukları arazi çalışmalarında, bölgede yol genişletme ve hızlı konut yapımı dâhil olmak üzere hızlı kalkınmanın dramatik çevresel değişikliklere yol açtı̆̆ını vurgulayarak çalışmayla aynı sonuçları sözel olarak elde etmişlerdir.

Çalışma alanında peyzaj göstergeleri, peyzajdaki parçalılığı ölçmede ve arazi kullanımıarazi örtüsünde gerçekleşen değişimin şiddetini göstermede başarılı olmuştur. $\mathrm{Bu}$, coğrafi bilgi sistemleri, uzaktan algılama ve peyzaj ekolojisinin peyzajın sürdürülebilirliğinde ve geleceğe yönelik planlamalarda destekleyici araçlar olduğunu ortaya koymuştur. Bu çalışmada geçmişe ilişkin fauna ve flora kayıtları bulunmadığından peyzaj patern değişimine bağlı olarak izolasyonun artması, homojenliğin azalmasının ve dolayısı ile habitat kalitesinde meydana gelen değişiminin türler üzerindeki etkisi araştırılamamıştır. Ayrıca peyzaj göstergeleri, sınıflandırma detayına hassastır (Turner vd., 2001) Bu nedenle burada incelenen çalışma alanında farklı sınıflandırma kriteri kullanılırsa sonuçlar da değişebilecektir. 


\section{Referanslar}

Alphan, H. (2006) “Ekosistem Dinamiklerinin İzlenmesine Bir Araç Olarak Peyzaj Değişimlerinin Analizi”, Ekoloji 15 (58): 8-15.

Bastian, O. (2001) “Landscape ecology: towards a unified discipline?”, Landscape Ecology 16: 757-766.

Coppedge, B.R.; Engle, D.M.; Fuhlendorf, S.D.; Masters, R.E.; Gregory. M.S. (2001) "Landscape cover type and pattern dynamics in fragmented southern Great Plains grasslands", Landscape Ecology 16 (8): 677-690.

Crews-Meyer, K.A. (2001) “Assessing landscape change and population-environment interactions via panel analysis”, Geocarto International 16 (4): 69-79.

Dilek, F.E.; Uzun, O. (2007) “Düzce Asarsuyu Havzasında Peyzaj Değişimi”, Ekoloji Dergisi 17 (65): 36-44.

Fahrig, L. (1997) "Relative affects of habitat loss and fragmentation on population extinction", Journal of Wildlife Management 61(3): 603-610.

Forman, R.T.T.; Godron, M. (1986) Landscape Ecology. John Wiley and Sons, Inc., New York.

Groom, G.; Mucher, C.A.; Ihse, M.; Wrbka, T. (2006) "Remote sensing in landscape ecology: experiences and perspectives in a European context", Landscape Ecology 21: 391-408.

Harper, K.A.; MacDonald, S.E.; Burton, P.J.; Chen, J.; Brosofske, K.D.; Saunders, S.C.; Euskirchen, E.S.; Roberts, D.; Jaiteh, M.S.; Esseen, P. (2005) "Edge influence on forest structure and composition in fragmented landscapes", Conservation Biology 19(3): 1-15.

Hitchings, S.P.; Beebee, T.J.C. (1998) "Loss of genetic diversity and fitness in Common Toad (Bufo bufo) populations isolated by inimical habitat", J Evol Biol 11: 269-283.

Hurley, P.T.; Arı, Y. (2011) "Mining (Dis)amenity: the political ecology of mining opposition in the Kaz (Ida) Mountain region of western Turkey", Development and Change 42 (6): 1393-1415.

İrtem, E.; Karaman, E. (2004) "Edremit Küçükkuyu arasındaki turizm faaliyetlerinin kıyı alanlarına etkisi ve önerilen yönetim programı”, ITÜ Mühendislik Dergisi 3 (1): 3-14

İrtem, E.; Kabdaşl1, S.; Azber, N. (2005) "Coastal zone problems and environmental strategies to be implemented at Edremit Bay, Turkey", Environmental Management 36 (1): 37-47.

Jensen, J.R. (2000) Remote Sensing of the Environment an Earth Resource Perspective. Prentice Hall Series in Geographic Information Science, Upper Saddle River, New Jersey.

Johnson, D.H.; Schwartz, M.D. (1993) “The conservation reserve program and grassland birds", Conservation Biology 7: 934-937.

Kocadağlı, A.Y. (2009) “Türkiye'de zeytincilik faaliyetlerinde Edremit Körfezi kıyllarının önemi”, İstanbul Üniversitesi Edebiyat Fakültesi Coğrafya Bölümü Coğrafya Dergisi 19 : 28-58.

Lavers, C.; Haines-Young, R. (1993) "Equilibrium Landscapes and Their Aftermath: Spatial Heterogeneity and the Role of New Technology”, In: Haines-Young R, Green D, Cousins S (eds.), Landscape Ecology and Geographic Information System, London: 57-74.

Lo Gullo, A.M.; Salleo. S. (1988) "Different strategies of drought resistance in three Mediterranean sclerophyllous trees growing in the same environmental conditions", New Phytol. 108: 267-276.

Loumou, A.; Giourga, C.H.; Dimitrakopoulos, P.; Koukoulas, S. (2000) "Tourism contribution to agro-ecosystems conservation; the case of Lesbos island, Greece", Environmental Management 26(4): 363-370.

Marsh, G.P. (1864) Man and Nature: or Physical Geography as Modified by Human Action. Harvard University Press, Cambridge.

McGarigal, K.; Marks, B.J. (1995) FRAGSTATS: Spatial Pattern Analysis Program for Quantifying Landscape Structure. Department of Agriculture Forest Service, General Technical Report, PNW-GTR-351, Portland, Oregon. 
McGarigal, K.; Cushman, S.A. (2002) "Comparative evaluation of experimental approaches to the study of habitat fragmentation effects”, Ecological Applications 12(2): 335-345.

Messina, J.P.; Crews-Meyer, K.A.; Walsh, S.J. (2000) “Scale Dependent Pattern Metrics and Panel Data Analysis as Applied in a Multiphase Hbrid Land Cover Classification Scheme", In: Proceedings of the American Society of Photogrammetry and Remote Sensing, ASPRS Conference in 2000, Miami, FL, USA.

Migliorini, P. (2011) "Development of Organic Olive Cultivation and Its Iportance for the Sustainability in the Mediterranean” In: Migliorini, Paola; Minotou, Charikleia; Lusic, Drazen; Hashem, Yousry and Martinis, Aristotelis (Eds.) Book of abstract. International Conference on Organic Agriculture and Agro-Eco Toursim in the Mediterranean, DIO.

Milne, B.T. (1988) "Measuring the fractal geometry of landscapes", Applied Mathematics and Computation, 27: 67-79.

Milne, B.T. (1991) "Lessons From Applying Fractal Models to Landscape Patterns", Quantitative Methods in Landscape Ecology. (eds. M.G. Turner \& R.H. Gardner ). New York, Springer-Verlag: 199-235.

Myers, N.; Mittermeier, R.A.; Mittermeier, C.G.; da Fonseca, G.A.B.; Kent, J. (2000) "Biodiversity hotspots for conservation priorities", Nature 403: 853-858.

Naveh, Z.; Dan, J. (1973) The Human Degradation of Mediterranean Landscapes in Israel. In: Castri F, Mooney HA (eds.), Mediterranean-Type Ecosystems, Origin and Structure, Springer-Verlag, New York: 370-390.

Newton, A.C.; Hill, R.A.; Echeverria, C.; Golicher, D.; Rey Benayas, J.M.; Cayuela, L.; Hinsley, S.A. (2009) "Remote sensing and the future of landscape ecology", Progress in Physical Geography 33: 528-546.

Primack, R.B. (1998) Essentials of Conservation Biology. Second Edition, Sinauer Associates, Inc. Sunderland, Massachusetts.

Riebsame, W.E.; Meyer, W.B.; Turner, B.L. (1994) "Modeling land-use and cover as part of global environmental change", Climate Change 28: 45.

Stanners, D.; Bourdeau, P. (eds.) (1995) Europe's environment: the Dobris assessment. European Environment Agency, Luxembourg. Environmental Assessment Report no. 1. [http://reports.eea.eu.int/92-826-5409-5/en/ tab_content_RLR].

Tağıl, Ş. (2006) "Peyzaj Patern Metrikleriyle Balıkesir Ovası ve Yakınında habitat parçalılığında ve kalitesinde meydana gelen değişim (1975-2000)", Ekoloji Dergisi 15 (60): 24-36.

Thomas, W.L. (1956) Man's Role in Changing the Face of the Earth. University of Chicago Press, Chicago.

Turner, M.G.; Ruscher, C.L. (1988) Changes in the spatial patterns of lands use in Georgia. Landscape Ecology 1: 241-251.

Turner, M.G. (1989) "Landscape ecology: The effect on pattern on process", Annual Review of Ecology and Systematics 20: 171-197

Turner, M.G.; Gardner, R.H.; O’Neill, R.V. (2001) Landscape Ecology in Theory and Practice: Pattern and Process. Springer- Verlag, New York.

Tzanopoulos, J.; Mitchley, J.; Pantis, J. (2005) "Modeling the effects of human activity on the vegetation of a northeast Mediterranean island", Applied Vegetation Science 8: 27-38.

UNEP. (1989) State of the Mediterranean Marine Environment. MAP Technical Report Series 28, Athens, Greece.

Wickware, G.M.; Howarth, P.J. (1981) "Change detection in the Peace-Athabasca Delta using digital landsat data", Remote Sensing of Environment 11: 9-25.

Wiens, J.A.; Moss, M.R. (1999) “Issues in Landscape ecology” International Association for Landscape Ecology fifth world congress, Snowmass Village, Colorado, USA, 1999. International Association for Landscape Ecology, Guelph.

Wilcox, B.A.; Murphy, D.D. (1985) “Conservation strategy: The effects of fragmentation on extinction”, American Naturalist 125: 879-887. 